\title{
Thymidine Kinase Measurement
}

National Cancer Institute

\section{Source}

National Cancer Institute. Thymidine Kinase Measurement. NCI Thesaurus. Code C120665.

The determination of the thymidine kinase present in a sample. 